UDC 316.342 .6

LBC 60.59

\title{
PRACTICE OF SOCIALAND MEDICAL CARE FOR ELDERLY PATIENTS WITH CARDIOVASCULAR DISEASES IN VOLGOGRAD REGION
}

\author{
Yulia A. Zimina \\ Volgograd State University, Volgograd, Russian Federation \\ Sergey A. Linchenko \\ Volgograd State University, Volgograd, Russian Federation \\ Margarita V. Postnova \\ Volgograd State University, Volgograd, Russian Federation \\ Galina A. Sroslova \\ Volgograd State University, Volgograd, Russian Federation
}

\begin{abstract}
Currently, the first place among the causes of mortality and disability of the adult population of the Russian Federation is occupied by cardiovascular diseases. According to the reporting documentation of the Health Committee of the Volgograd region for three quarters of 2019, at the expense of the federal budget in the conditions of federal specialized medical institutions, high-tech medical care was provided to 2615 residents of the Volgograd region. Over three quarters of 2019, high-tech medical care was provided to 868 patients in budget health-care institutions of the Volgograd region. The following medical care profiles are in the leading positions: cardiovascular surgery (904 patients treated), traumatology and orthopedics (820 patients treated), oncology (498 patients treated). The development of cardiovascular diseases is based on physiological factors (especially the human body, etc.) and social factors (lifestyle, alcoholism, etc.). A statement of the influence of both physiological and social factors on the health of the cardiovascular system actualizes the need to study the experience of preventive work and the provision of social and medical assistance in a unified system of social protection of the population of the Volgograd region. The main elements of this system are institutions and organizations with different functions - prevention, treatment and rehabilitation. Because the fact that the profiles of institutions providing services to people with cardiovascular diseases are different, the task of comprehensive support cannot be solved without a well-functioning mechanism for the interaction of all elements of assistance aimed at reducing the incidence and mortality rate from cardiovascular diseases. The work explores the activities of the Committee for Social Protection of the Volgograd Region as an organization that coordinates the work on building a system of prevention, treatment, and rehabilitation of older people, including those with cardiovascular diseases. Problems are systematized on the basis of a comprehensive review of theoretical approaches, the regulatory framework, and the results of an analysis of the work of medical and social institutions in the Volgograd Region, that impede the establishment of integrated work with patients who have cardiovascular pathology and do not allow building effective work.
\end{abstract}

Key words: medical and social assistance, cardiovascular diseases, social protection of the population, prevention, rehabilitation, medical examination. 
УДК 316.342 .6

ББК 60.59

\title{
ПРАКТИКИ РЕАЛИЗАЦИИ В ВОЛГОГРАДСКОЙ ОБЛАСТИ СОЦИАЛЬНОЙ И МЕДИЦИНСКОЙ ПОМОЩИ ПОЖИЛЫМ ПАЦИЕНТАМ С ЗАБОЛЕВАНИЯМИ СЕРДЕЧНО-СОСУДИСТОЙ СИСТЕМЫ
}

\author{
Юлия Александровна Зимина \\ Волгоградский государственный университет, г. Волгоград, Российская Федерация \\ Сергей Анатольевич Линченко \\ Волгоградский государственный университет, г. Волгоград, Российская Федерация \\ Маргарита Викторовна Постнова \\ Волгоградский государственный университет, г. Волгоград, Российская Федерация \\ Галина Алексеевна Срослова \\ Волгоградский государственный университет, г. Волгоград, Российская Федерация
}

\begin{abstract}
Аннотация. В настоящее время первое место среди причин смертности и инвалидизации взрослого населения Российской Федерации занимают сердечно-сосудистые заболевания. Согласно отчетной документации Комитета здравоохранения Волгоградской области за три квартала 2019 г. за счет средств федерального бюджета в условиях федеральных специализированных медицинских учреждений высокотехнологичная медицинская помощь оказана 2615 жителям Волгоградской области. В медицинских организациях Волгоградской области бюджетного типа за три квартала 2019 г. высокотехнологичная медицинская помощь оказана 868 пациентам. На лидирующих позициях находятся следующие профили медицинской помощи: «сердечно-сосудистая хирургия» (пролечено 904 пациента), «травматология и ортопедия» (пролечено 820 пациентов), «онкология» (пролечено 498 пациентов). В основе развития сердечно-сосудистых заболеваний лежат как физиологические факторы (особенности организма человека и др.), так и социальные факторы (образ жизни, алкоголизм и др.). Констатация их влияния на здоровье сердечно-сосудистой системы актуализирует необходимость исследования опыта профилактической работы и оказания социальной и медицинской помощи в единой системе социальной защиты населения Волгоградской области. Основными элементами данной системы являются учреждения и организации с разными функциями - профилактики, лечения и реабилитации. В связи с тем, что профили учреждений, оказывающих услуги лицам с сердечно-сосудистыми заболеваниями, разные, задача комплексной помощи не может быть решена без отлаженного механизма взаимодействия всех элементов помощи, направленной на снижение уровня заболеваемости и смертности от сердечно-сосудистых заболеваний. В работе исследована деятельность Комитета социальной защиты населения Волгоградской области как организации, осуществляющей координацию работы по выстраиванию системы профилактики, лечения и реабилитации пожилых людей, в том числе с сердечно-сосудистыми заболеваниями. На основе комплексного обзора теоретических подходов, нормативной базы, результатов анализа работы медицинских и социальных учреждений Волгоградской области систематизированы проблемы, препятствующие выстраиванию комплексной работы с пациентами, имеющими сердечно-сосудистую патологию, и не позволяющие выстроить эффективную работу.

Ключевые слова: медико-социальная помощь, сердечно-сосудистые заболевания, социальная защита населения, профилактика, реабилитация, диспансеризация.
\end{abstract}

Обсуждение. Сегодня в большинстве стран, занимающих ведущее положение в мировой экономике, заболевания, связанные с сердечно-сосудистой патологией, являются лидерами среди причин инвалидизации и смертности, при этом их распространенность в разных регионах значительно колеблется [Ога- нов 2009]. В Европе от сердечно-сосудистых заболеваний ежегодно умирают около 3 млн чел., в США - 1 млн, что в 2,5 раза больше, чем от всех злокачественных новообразований, причем четвертую часть умерших от сердечно-сосудистых заболеваний составляют люди в возрасте от 65 лет [Gibbons et al. 2013]. 
Главной причиной смертности населения России также являются заболевания сердечнососудистой системы. Если в 1939 г. они составляли лишь $11 \%$ случаев со смертельным исходом, то сегодня - свыше $50 \%$, особенно высокий уровень смертности у мужского населения [Чазова, Калинина, Иванов 2012].

Литературу по проблеме можно условно разделить на две группы источников и исследований. Первая из них - это работы авторов, исследующих проблемы развития социальных технологий профилактики и реабилитации заболеваний, в том числе сердечно-сосудистой системы. Это работы Е.И. Холостовой [Холостова 2016]; Г.И. Нечаевой, Е.А. Темниковой, Г.И. Боридько и Л.Д. Солодниковой [Нечаева и др. 2009]. Монография А.Б. Тугарова, М.Э. Целина и Т.И. Лавренова посвящена рассмотрению всего комплекса проблем, связанных с оказанием социально-медицинской помощи населению и подготовкой специалистов в этой области социальной работы [Тугаров, Целина, Лавренова 2005]. Работа Л.Н. Семченко глубоко и полно рассматривает место социального работника в системе здравоохранения, особо выделяя аспект социально-медицинской помощи семье [Семченко 2006].

Второе направление составляют медицинские работы, в которых данные вопросы рассматриваются в ключе лечебной практики и специфики работы медицинских учреждений. Изучаемая проблема нашла отражение в работах Л.А. Бокерия, ведущего кардиохирурга страны, в силу чего их отличает и узкопрофессиональный подход, и рассмотрение проблемы на обобщающем, общегосударственном уровне [Бокерия и др. 2008]. Значительную часть работ составляют труды по медицинской проблематике, не рассматривающие проблемы межведомственного взаимодействия медицинских и социальных организаций. Так, в работе С.А. Шальновой исследованы вопросы лечения и контроля заболеваемости в России [Шальнова и др. 2011], В.С. Гасилина, Б.А. Сидоренко рассматривают сущность сердечно-сосудистых заболеваний, причины их возникновения и вопросы профилактики [Гасилин, Сидоренко 2009]. Профилактика таких болезней анализируется в работах Л.В. Чазовой, А.М. Калининой (напр.: [Калинина, Чазова 2013]). Н.В. Данилова в сво- их работах рассматривает вопросы совершенствования организации восстановительного лечения и реабилитации работающего населения (напр.: [Данилова 2009]). Диагностика, основные принципы лечения и профилактика сердечно-сосудистых заболеваний рассматриваются в работах В.А. Епифанова, Ю.С. Поповой и других исследователей [Епифанов 2013; Попова 2011].

Целью данной работы является изучение опыта оказания медико-социальной помощи отдельным категориям граждан на примере специализированной медицинской помощи пожилым людям с заболеваниями сердечно-сосудистой системы. Авторы делают попытку выявить и проанализировать особенности региональной системы оказания медикосоциальной помощи и проблемы межведомственного взаимодействия.

Система социально-медицинской профилактики. Одним из направлений профилактики заболеваний является проведение диспансеризации. Она включает в себя комплексные меры по наблюдению за здоровьем пожилых людей и состоит из диагностики, профилактики, лечения с целью поддержания активного долголетия. Диспансеризация способствует снижению уровня инвалидности и смертности, увеличению продолжительности жизни населения в Российской Федерации.

Главная задача управления медицинской помощью диспансеризуемых по сердечно-сосудистому профилю заболеваний - формирование оптимального уровня эффективности и качества оздоровительных мероприятий, проводимых среди населения. Решение этой задачи зависит от своевременности и полноты контроля за состоянием здоровья диспансеризуемого, окружающей среды и комплекса проводимых оздоровительных мероприятий. Принципиальным подходом в решении этой проблемы является организация дифференцированного наблюдения в зависимости от состояния здоровья диспансеризуемых. Строгая регламентация такой системы наблюдения выполняется на основе комплекса социальногигиенических, медико-биологических и организационно-тактических стандартов. Их комплекс включает в себя как основной, так и совокупность специальных и вспомогательных стандартов, предназначающихся для 


\section{НАУЧНЫЕ СООБЩЕНИЯ}

обеспечения качества и эффективности диспансерного метода обслуживания. Определяющим из них должен быть основной стандарт, с помощью которого описывается состояние здоровья диспансеризуемого. Он является стержнем содержания групп дифференцированного наблюдения на специальных основах, состоящих из отдельных компонентов: оценка окружающей среды по критериям здоровья (социально-гигиеническая компонента комплексной оценки); оценка текущего медикобиологического состояния диспансеризуемого по критериям состояния сердечно-сосудистой патологии (медико-биологическая компонента комплексной оценки).

Дополнительные стандарты комплекса диспансерных мероприятий развивают принцип основного стандарта дифференцированного наблюдения. Они построены на диагностических и лечебно-профилактических компонентах. Объем и вид стандартных мероприятий определяются из принципа первичной и вторичной профилактики, а в последующем - характером течения болезни. Организационные специальные стандарты конкретизируют укрепленные задачи основного и вспомогательного стандарта, указывают на метод и пути достижения цели. Знание каждого из них выбрано таким образом, чтобы не допустить дублирования или подмены действий. Регламентация кратности и длительности наблюдения в каждой группе определяется состоянием здоровья. С установлением контрольных сроков предусмотрена ответственность исполнителей за полное осуществление оздоровительных мероприятий.

Организация лечения сердечно-сосудистых заболеваний. Порядок оказания неотложной помощи населению Российской Федерации при болезнях сердца и системы кровообращения кардиологического профиля соответствует Приказу Министерства здравоохранения и социального развития Российской Федерации от 19 сентября 2009 г. № 599н «Об утверждении Порядка оказания плановой и неотложной медицинской помощи населению Российской Федерации при болезнях системы кровообращения кардиологического профиля». Данный приказ является основным нормативным документом, который регулирует порядок оказания медицинской помощи населению
РФ при болезнях сердечно-сосудистой системы. Согласно этому документу неотложной медицинской помощи требуют такие состояния, как:

- внезапная сердечная смерть;

- тромбоэмболия легочной артерии;

- кардиогенный шок;

- гипертонический криз;

- нарушения ритма и проводимости сердца;

- расслаивающая аневризма аорты и др.

Неотложная медицинская помощь пациентам с заболеваниями сердечно-сосудистой системы кровообращения состоит из двух этапов: первый - догоспитальный (скорая медицинская помощь); второй - стационарный, осуществляемый в блоках интенсивной терапии кардиологических отделений или в отделениях реанимации и интенсивной терапии.

Порядок госпитализации кардиологических больных в Волгоградской области закреплен следующими нормативными документами: соглашением от 09.02.2019 № 056-08-2019-143 «О предоставлении из федерального бюджета бюджету Волгоградской области субсидии в целях софинансирования расходов, возникающих при оказании гражданам Российской Федерации высокотехнологичной медицинской помощи, не включенной в базовую программу обязательного медицинского страхования» и Постановлением Правительства Российской Федерации от 10.12.2018 № 1506 «О Программе государственных гарантий бесплатного оказания гражданам медицинской помощи на 2019 год и на плановый период 2020 и 2021 годов». Согласно этим и иным нормативным документам госпитализация производится в соответствии со специализацией того или иного медицинского учреждения, ближайшего к месту расположения больного. Так, например, пациенты с острыми инфарктами миокарда, а также с подозрением на острую коронарную патологию госпитализируются в следующие кардиологические отделения: МУЗ «Клиническая больница № 4», МУ3 «ГКБСМП № 25», НУ3 «Отделенческая клиническая больница на ст. Волгоград-1 ОАО «РЖД»; МУЗ «Клиническая больница № 7», МУЗ «КБСМП № 15», МУЗ «Больница № 16». Госпитализация пациентов с нестабильной стенокардией осуществляется МУЗ «Клиническая 
больница № 4», МУЗ «ГКБСМП № 25»; МУЗ «Клиническая больница № 7», НУЗ «ВОКБ ст. Волгоград-1», МУЗ «КБСМП № 15». Если пациент имеет кардиостимулятор, то при неисправности устройства больной направляется в кардиологическое отделение по месту жительства, а после лечения - на консультацию с заведующим сосудистым отделением МУЗ «ГКБСМП № 25».

Система реабилитации сердечнососудистых заболеваний. Современные технологии, применяемые в Центре реабилитации «Волгоград» в работе с пациентами сердечно-сосудистой патологией, позволяют добиваться высоких и положительных результатов. Основной задачей является проведение реабилитации больных, перенесших инфаркт миокарда, инсульт, реконструктивные операции на коронарных сосудах сердца (АКШ, баллонная ангиопластика). Отбор больных проводит клинико-экспертная комиссия клинических больниц Волгограда и области, г. Волжского, г. Элисты. В кардиологическом отделении уделяется большое внимание психологическому аспекту реабилитации, современной коррекции имеющихся психологических отклонений у больного с помощью психотерапевтических методов. За 5 лет работы положительный эффект реабилитации достигнут у 95-97 \% больных, а у 3-5 \% - ухудшения были связаны с клиническими особенностями течения заболевания.

Особое внимание уделяется кардиологической реабилитации, позволяющей избежать инвалидности и вернуться к нормальной физической активности, снижающей риск рецидивов заболевания и риск летального исхода, позволяющей снизить дозы лекарственных препаратов, минимизировать страх, тревогу и депрессию и улучшить физическое состояние пациента, повысить качество жизни. Реабилитация направлена на постепенное восстановление физической формы, работоспособности, психологического состояния больного. С этой целью пациентам назначаются программы физических тренировок в виде ЛФК, ходьбы, в том числе и популярной сейчас скандинавской ходьбы, а также специальные физические тренировки по программе «Спринт» (индивидуальные занятия в бассейне). Перед началом курса реабилитации проводят оцен- ку уровня физической подготовки пациента. Программу реабилитации, комплексы упражнений, их продолжительность и интенсивность разрабатывает лечащий врач, основываясь на возрасте, весе пациента, тяжести заболевания, наличии сопутствующих заболеваний. Важным аспектом реабилитационных мероприятий является индивидуальная программа психологической помощи, физических тренировок, исходя из индивидуальных особенностей и состояния здоровья каждого пациента.

Санаторный этап реабилитации - это проведение восстановительных мероприятий. В Центре санаторной реабилитации «Волгоград» созданы все условия для эффективного восстановительного лечения кардиологических больных с использованием современных технологий, что в итоге повышает качество жизни пациента. Подтверждением эффективности работы Центра являются данные по составу пациентов в кардиологическом отделении по нозологическим формам и эффективность их долечивания (реабилитации) в ФГУ ЦР ФСС РФ «Волгоград» в 2017 г. (см. таблицу).

Как видно из представленных результатов, положительный эффект реабилитации достигнут у подавляющего большинства пациентов, в среднем у $96 \%$ больных, а у $3,5 \%$ больных ухудшения были связаны с клиническими особенностями течения заболевания. Реабилитационное лечение не заканчивается по выписке из стационара, а продолжается в поликлинических и домашних условиях, что обусловливает важность диспансерного обслуживания.

Система межведомственного взаимодействия при профилактике и лечении сердечно-сосудистых заболеваний. При реализации медико-социальной помощи в отношении пациентов, страдающих сердечнососудистыми заболеваниями, важнейшее значение имеют технологии социальной работы. Нередко у сотрудников медицинских и социальных учреждений при работе с такими пациентами возникают проблемы, которые выходят за рамки их профессиональной компетентности и препятствуют успешной узкопрофессиональной деятельности. Волгоградская область выступает площадкой по реализации целого ряда мероприятий как федерального, 


\section{НАУЧНЫЕ СООБЩЕНИЯ}

так и местного уровня, призванных наладить межведомственное взаимодействие по организации медицинской и социальной помощи населению. Деятельность осуществляется в соответствии с Приказом Министерства труда и социальной защиты населения РФ от 29.06.2018 № 435 «О реализации пилотного проекта по созданию системы долговременного ухода за гражданами пожилого возраста и инвалидами», Соглашением о взаимодействии между Администрацией Волгоградской области, автономной некоммерческой организацией «Агентство стратегических инициатив по продвижению новых проектов» и Благотворительным фондом помощи пожилым людям и инвалидам «Старость в радость» в рамках реализации пилотного проекта по созданию системы долговременного ухода за гражданами пожилого возраста и инвалидами, включающей сбалансированное социальное обслуживание и медицинскую помощь на дому, в полустационарной и стационарной форме с привлечением патронажной службы и сиде- лок и Постановлением губернатора Волгоградской области от 18 января 2019 г. «Об утверждении Плана мероприятий («дорожной карты») по созданию на территории Волгоградской области системы долговременного ухода за гражданами пожилого возраста и инвалидами, признанными нуждающимися в социальном обслуживании, в рамках федерального проекта «Старшее поколение» национального проекта «Демография».

С 2016 г. Волгоградский регион в числе пяти субъектов Федерации реализует пилотный проект Минздрава РФ «Территория заботы» (в 2019 г. список регионов расширен). Его цель - создание долгосрочной модели организации медицинской и социальной помощи представителям старшего поколения, в основе которой лежит межведомственный и междисциплинарный подход. Разработана и апробирована технология организации долговременного ухода за людьми пожилого возраста в пяти муниципальных районах Волгоградской области - Николаевском, Октябрьском,

Состав больных в кардиологическом отделении по нозологическим формам и эффективность долечивания (реабилитации) в ФГУ ЦР ФСС РФ «Волгоград»

\begin{tabular}{|c|c|c|c|c|c|c|c|}
\hline \multirow[t]{2}{*}{ Заболевание } & \multirow[t]{2}{*}{ Всего } & \multicolumn{2}{|c|}{ Улучшение } & \multicolumn{2}{|c|}{ Без изменений } & \multicolumn{2}{|c|}{ Ухудшение } \\
\hline & & $\begin{array}{l}\text { Абсолютное } \\
\text { число }\end{array}$ & $\%$ & $\begin{array}{l}\text { Абсолютное } \\
\text { число }\end{array}$ & $\%$ & $\begin{array}{l}\text { Абсолютное } \\
\text { число }\end{array}$ & $\%$ \\
\hline $\begin{array}{lll}\text { Инфаркт } & \text { миокарда } & \text { c } \\
\text { зубцом Q } & & \\
\end{array}$ & 236 & 222 & 94 & 3 & 1 & 11 & 5 \\
\hline $\begin{array}{l}\text { Инфаркт миокарда } \\
\text { зубца Q }\end{array}$ & 92 & 89 & 97 & 0 & 0 & 3 & 3 \\
\hline $\begin{array}{l}\text { Нестабильная стенокар- } \\
\text { дия }\end{array}$ & 112 & 109 & 97 & 0 & 0 & 3 & 3 \\
\hline $\begin{array}{l}\text { Состояние после опера- } \\
\text { ции аортокоронарного } \\
\text { шунтирования }\end{array}$ & 66 & 65 & 98 & 0 & 0 & 1 & 1 \\
\hline $\begin{array}{l}\text { Состояние после опера- } \\
\text { ций транслюминальной } \\
\text { баллонной ангиопласти- } \\
\text { ки и стентирования }\end{array}$ & 21 & 20 & 95 & 0 & 0 & 1 & 5 \\
\hline $\begin{array}{l}\text { Состояние после опера- } \\
\text { ции протезирования кла- } \\
\text { панов сердца }\end{array}$ & 31 & 30 & 97 & 0 & 0 & 1 & 3 \\
\hline $\begin{array}{l}\text { Состояние после опера- } \\
\text { ции на сердце и магист- } \\
\text { ральных сосудов }\end{array}$ & 10 & 8 & 80 & 0 & 0 & 2 & 20 \\
\hline $\begin{array}{l}\text { Состояние после опера- } \\
\text { ции на сосудах нижних } \\
\text { конечностей }\end{array}$ & 1 & 1 & 100 & 0 & 0 & 0 & 0 \\
\hline $\begin{array}{l}\text { Артериальная гипертен- } \\
\text { зия и ИБС } \\
\end{array}$ & 66 & 66 & 100 & 0 & 0 & 0 & 0 \\
\hline Bсего & 635 & 610 & 96,0 & 3 & 0,5 & 22 & 3,5 \\
\hline
\end{tabular}


Палласовском, Фроловском и Камышинском. На их территории организованы мобильные межведомственные группы из представителей медучреждений и системы соцзащиты населения, которые выявляют одиноких, одиноко проживающих стариков, а также тех из них, кто нуждается в первоочередной медицинской и социальной помощи, в том числе и кардиологической, организована служба сиделок, созданы стационары на дому и сопровождаемое проживание малых групп инвалидов. В Волгоградской области сформированы специальные гериатрические бригады. Их задачей является выезд на дом к маломобильным пациентам пожилого и старческого возраста для решения таких задач, как проведение осмотра пациента врачами-специалистами; проведение диспансеризации; проведение лечебных процедур и манипуляций; проведение лечения в дневном стационаре на дому; определение нуждаемости гражданина в предоставлении социальных услуг в стационарной форме, форме социального обслуживания на дому; иные вопросы, касающиеся организации и предоставления мер медико-социальной помощи лицам пожилого и старческого возраста.

В лечебных заведениях Волгограда и области существуют штатные сотрудники, которые реализуют на практике социальные технологии, включающие три основные группы: медико-ориентированные, социально-ориентированные и интегративные.

Медико-ориентированные технологии в социальной работе относительно категории пожилых граждан включают организацию как медицинской, так и социальной помощи больным; мероприятия по предупреждению возникновения рецидивов; сопровождение при оформлении инвалидности, при наступлении факта смерти и в нормативно-правовых вопросах.

Социально-ориентированные технологии в Волгограде и регионе относительно работы с гражданами «третьего возраста» составляют меры социально-правовой защиты граждан по охране здоровья и оказания медицинской и социальной помощи. Социальные работники представляют интересы лиц, нуждающихся в данном виде помощи, в органах местной власти. В городе существует реабили- тационная социально-бытовая инфраструктура, которая информирует население по вопросам здорового образа жизни и о различных видах социальной защиты. Социальные работники содействуют решению различных проблем пожилых граждан.

Особое место сегодня занимают интегративные технологии работы с пожилыми пациентами, позволяющие осуществлять комплексную оценку социального статуса клиента, формировать установку пациента на здоровый образ жизни, проводить медико-социальную экспертизу. Данные технологии позволяют успешно осуществлять медицинскую, социальную и профессиональную реабилитацию инвалидов, социально-правовое консультирование и помогают в разработке комплексных программ медико-социальной помощи.

Результаты. Итогом исследования стали следующие выводы о функционировании системы медико-социальной помощи пожилым пациентам:

1. Основными составляющими данной системы являются лечебные, реабилитационные, профилактические учреждения и выполняемые ими функции.

2. Уровень эффективности работы рассматриваемой системы можно оценить как достаточно высокий.

3. Ведущая роль по реабилитации кардиологических больных в Волгоградской области принадлежит Центру реабилитации «Волгоград». По данным за 2017 г., доля пациентов, состояние которых улучшилось после программ реабилитации, составила $96 \%$.

4. Главная роль в реализации профилактической составляющей принадлежит диспансеризации населения в амбулаторно-поликлинических учреждениях. Деятельность центров специализированной медпомощи и диспансеров (кардиологических), осуществляющих диагностические, профилактические и лечебно-оздоровительные мероприятия, повышает качество жизни пациентов и способствует их активному долголетию.

5. Реализация социальных технологий при организации медико-социальной помощи пожилым пациентам, страдающим сердечно-сосудистыми заболеваниями, в медицинских учреждениях Волгограда и области позволяет достичь следующих важных результатов: 
обеспечить оптимальную связь пациента с его социальным окружением; оптимизировать самопомощь пациента и поддержку родственников; обеспечить связь работников медицинского учреждения с семьей пациента и др.

На территории региона продолжается реализация мероприятий по оптимальному развитию сети служб ранней помощи и обеспеченности населения услугами ранней помощи с учетом возрастного состава и плотности населения, транспортной инфраструктуры и других факторов, влияющих на доступность и качество услуг ранней помощи, в том числе в рамках подпрограммы «Формирование системы комплексной реабилитации и абилитации инвалидов» государственной программы Волгоградской области «Социальная поддержка и защита населения Волгоградской области». В подпрограмму включены мероприятия на трехлетний период по оснащению современным реабилитационным оборудованием и методиками организаций социального облуживания, по повышению квалификации и профессиональной переподготовки специалистов, работающих с пациентами с сердечнососудистыми заболеваниями.

\section{СПИСОК ЛИТЕРАТУРЫ}

Бокерия и др. 2008 - Бокерия Л.А., Ступаков И.Н., Самородская И.В., Болотова Е.В., Фуфаев Е.Н. Оптимизация расчета потребности кардиохиругической помощи больным с сердечно-сосудистыми заболеваниями // Здравоохранение РФ. 2008. №4. C. 25-27.

Гасилин, Сидоренко 2009 - Гасилин В.С., Сидоренко Б.А. Сердечно-сосудистые заболевания. М.: Медицина, 2009.

Данилова 2009 - Данилова Н.В. Совершенствование организации восстановительного лечения и реабилитации работающего населения // Здравоохранение РФ. 2009. № 4. С. 23-27.

Епифанов 2013 - Епифанов В.А. Восстановительная медицина: справочник. М.: ГЭОТАР-Медиа, 2013.

Калинина, Чазова 2013 - Калинина А.М., Чазова Л.В. Многофакторный подход к профилактике ишемической болезни сердца среди населения (руководство для врачей). М.: Наука, 2013. Нечаева и др. 2009 - Нечаева Г.И., Темникова Е.А., Боридько Г.И., Солодникова Л.Д. Социальные вопросы амбулаторной медицинской помощи лицам старшей возрастной группы с хронической сердечной недостаточностью // Терапевтический архив. 2009. Т. 81, № 1. С. 12-15.

Оганов 2009 - Оганов Р.Г. Первичная профилактика ишемической болезни сердца. М.: Медицина, 2009.

Попова 2011 - Попова Ю.С. Болезни сердца и сосудов: лечение, диагностика, профилактика. СПб.: Крылов, 2011.

Семченко 2006 - Семченко Л.Н. Социальный работник в системе здравоохранения: социально-медицинская помощь семье. Челябинск: Изд-во Южно-Уральского гос. мед. ун-та, 2006.

Тугаров, Целина, Лавренова 2005 - Тугаров А.Б., Целина М.Э., Лавренова Т.И. Социально-медицинская помощь населению: вопросы теории, технологии, подготовки специалистов. Пенза: Изд-во Пензенского гос. пед. ун-та им. В.Г. Белинского, 2005.

Холостова 2016 - Холостова Е.И. Генезис отношения к пожилым людям в обществе // Отеч. журн. соц. работы. 2016. № 3. С. 53-57.

Чазова, Калинина, Иванов 2012 - Чазова Л.В., Калинина А.М., Иванов В.М. Профилактика сердечно-сосудистых заболеваний в деятельности врача практического здравоохранения // Здравоохранение РФ. 2012. № 6. С. 16-18.

Шальнова и др. 2011 - Шальнова С.А., Деев А.Д., Вихирева О.В., Гаврилова Н.Е., Оганов Р.Г. Распространенность артериальной гипертонии в России. Информированность, лечение, контроль // Профилактика заболеваний и укрепления здоровья. 2011. № 2. С. 3-7.

Gibbons et al. 2013 - Gibbons G.H., Shurin S.B., Mensah G.A., Lauer M.S. Refocusing the Agenda on Cardiovascular Guidelines // Circulation. 2013. Vol. 8, № 128 (15). P. 1713-1715.

\section{REFERENCES}

Bokeria L.A., Stupakov I.N., Samorodskaya I.V., Bolotov E.V., Fufayev E.N., 2008. Optimization of the Calculation of the Need for Cardiochirugic Care for Patients with Cardiovascular Diseases. Zdravoohranenie RF, no. 4, pp. 25-27.

Gasilin V.S., Sidorenko B.A., 2009. Heart-vascular diseases. Moscow, Medicina.

Danilova N.V., 2009. Improving the Organization of Rehabilitation Treatment and Rehabilitation of the Working Population. Zdravoohranenie $R F$, no. 4, pp. 23-27.

Epifanov V.A., 2013. Restorative Medicine: Reference Book. Moscow, GEOTAR-Media.

Calinina A.M., Chazova L.V., 2013. Multi-Factor Approach to Prevention of Ischemic Heart 
Disease Among the Population (Manual for Doctors). Moscow, Nauka.

Nechayeva G.I., Temnikov E.A., Boridko G.I., Solodnikova L.D., 2009. Social Issues of Outpatient Medical Care for Persons of Older Age Group with Chronic Heart Failure. Terapevticheskij arhiv, vol. 81, no. 1, pp. 12-15.

Oganov R.G., 2009. Primary Prevention of Ischemic Heart Disease. Moscow, Medicina.

Popova Y.S., 2011. Heart and Vascular Diseases: Treatment, Diagnosis, Prevention. Saint Petersburg, Krylov.

Semchenko L.N., 2006. Social Worker in the Health Care System: Social and Medical Care for the Family. Chelyabinsk, Izdatelstvo JuzhnoUralskogo gosudarstvennogo medicinskogo universiteta.

Tugarov A.B., Celina M.E., Lavrenova T.I., 2005. Social and Medical Assistance to the Population:
Issues of Theory, Technology, Training of Specialists. Penza, Izdatel'stvo Penzenskogo gosudarstvennogo pedagogicheskogo universiteta im. V.G. Belinskogo.

Kholostova E.I., 2016. Genesis of Attitude Towards Older People in Society. Domestic Journal of Social Work, no. 3, pp. 53-57.

Chazova L.V., Kinina A.M., Ivanov V.M., 2012. Prevention of Cardiovascular Diseases in the Activity of a Doctor of Practical Health Care, Zdravoohranenie $R F$, no. 6, pp. 16-18.

Shalnova S.A., Deev A.D., Vihireva O.V., Gavrilova N.E., Oganov R.G., 2011. Prevalence of Arterial Hypertension in Russia. Awareness, Treatment, Control. Profilaktika zabolevanij i ukreplenija zdorovja, no. 2, pp. 3-7.

Gibbons G.H., Shurin S.B., Mensah G.A., Lauer M.S., 2013. Refocusing the Agenda on Cardiovascular Guidelines. Circulation, vol. 8, no. 128 (15), pp. 1713-1715.

\section{Information About the Authors}

Yulia A. Zimina, Candidate of Sciences (Chemistry), Associate Professor of a Bioengineering and Bioinformatics, Volgograd State University, Prosp. Universitetsky, 100, 400062 Volgograd, Russian Federation, ziminaua@mail.ru, https://orcid.org/0000-0002-1017-531X

Sergey A. Linchenko, Senior Lecturer, Department of Sociology and Social Technologies, Volgograd State University, Prosp. Universitetsky, 100, 400062 Volgograd, Russian Federation, seanlinchenko@mail.ru, https://orcid.org/0000-0002-4727-2199

Margarita V. Postnova, Doctor of Sciences (Biology), Senior Researcher, Head of the Department of Bioengineering and Bioinformatics, Volgograd State University, Prosp. Universitetsky, 100, 400062 Volgograd, Russian Federation, postnova@volsu.ru, https://orcid.org/0000-0001-6988-6389

Galina A. Sroslova, Candidate of Sciences (Biology), Associate Professor of Bioengineering and Bioinformatics, Volgograd State University, Prosp. Universitetsky, 100, 400062 Volgograd, Russian Federation, biobio@volsu.ru, https://orcid.org/0000-0002-9118-7098

\section{Информация об авторах}

Юлия Александровна Зимина, кандидат химических наук, доцент кафедры биоинженерии и биоинформатики, Волгоградский государственный университет, просп. Университетский, 100, 400062 г. Волгоград, Российская Федерация, ziminaua@mail.ru, https://orcid.org/0000-0002-1017-531X

Сергей Анатольевич Линченко, старший преподаватель кафедры социологии и социальных технологий, Волгоградский государственный университет, просп. Университетский, 100, 400062 г. Волгоград, Российская Федерация, seanlinchenko@mail.ru, https://orcid.org/0000-0002-4727-2199

Маргарита Викторовна Постнова, доктор биологических наук, старший научный сотрудник, заведующая кафедрой биоинженерии и биоинформатики, Волгоградский государственный университет, просп. Университетский, 100, 400062 г. Волгоград, Российская Федерация, postnova@volsu.ru, https://orcid.org/0000-0001-6988-6389

Галина Алексеевна Срослова, кандидат биологических наук, доцент кафедры биоинженерии и биоинформатики, Волгоградский государственный университет, просп. Университетский, 100, 400062 г. Волгоград, Российская Федерация, biobio@volsu.ru, https://orcid.org/0000-0002-9118-7098 